\title{
An integrated land-use/transportation forecasting and planning model: A metropolitan planning support system
}

\author{
Ardeshir Anjomani \\ University of Texas at Arlington \\ anjomani@uta.edu
}

\begin{abstract}
Over the last several decades, land-use/transport interaction models have evolved. Although these models have the potential to become primary demographic forecasting and planning vehicles in metropolitan transportation planning for most large US urban regions, some gaps and improvements must be addressed.

This paper briefly discusses a newly developed and refined integrated land-use/transportation model. It also introduces innovative approaches to modeling an urban area,including a variant of a geographic information system-based land-use and environmental suitability analysis, as main components in deriving development potential for a small-cell grid of the study region. This approach enables the inclusion of public and stakeholder input into the modeling process, facilitates micro-level consideration of trip generation, trip distribution, and mode-choice inside the land-use demographic model, thus furthering the integration of transportation and land use in the modeling process. Such considerations and utilization of rule-based approaches and concerns of economic development and environmental and sustainability factors help close some existing gaps of operational models designed for realworld practical applications. All of these features contribute toward further improvement of these models.
\end{abstract}

Keywords: Metropolitan Integrated models, land use, transportation, planning support system, demographic forecasting

\section{Article history:}

Received: May 11, 2018

Received in revised form:

September 8, 2020

Accepted: September 9, 2020

Available online: January 5,

2021

\section{Introduction}

Over the last several decades, land-use/transportation planning processes have evolved to become the metropolitan planning vehicle to address operational needs in planning and policy decisions. Urban regions continue to plan to develop their urbanized areas using variants of these planning and modeling processes. Concerning land-use transportation modeling, the United States Department of Transportation (USDOT, 2004) identifies an accurate recognition of the complex relationships among urban form, land use, and travel demand as the first of five major issues related to land-use modeling relevant to a metropolitan planning organization (MPO).

Copyright 2021 Ardeshir Anjomani

http://dx.doi.org/10.5198/jtlu.2021.1412

ISSN: $1938-7849$ | Licensed under the Creative Commons Attribution - Noncommercial License 4.0

The Journal of Transport and Land Use is the official journal of the World Society for Transport and Land Use (WSTLUR) and is published and sponsored by the University of Minnesota Center for Transportation Studies. 
Land use demographic forecasting models provide primary input for travel demand models (TDMs). Yet, until recently, a rigorous and integrated application of such models in the land-use/transportation planning process has been scant (perhaps except for some of the largest metropolitan areas). Although recent theoretical and technological advances have brought further improvements to these models, they still maintain some deficiencies in bridging the gap to solve the multitude of problems in urban areas. Such issues include the effects of future developments on the environment, better modeling of metropolitan economic systems, input from stakeholders, ease of use for decision-makers, and better integration with the transportation modeling process. A need exists for a new model with a more flexible open structure and a different basis.

This paper presents a model that accommodates such a need to project the growth and decline of specific regional areas represented by employment and household changes in metropolitan region cells (or land parcels). We use a variant of a geographic information system (GIS)-based environmental and land suitability analysis as a principal component in the process of metropolitan-level integrated landuse transportation forecasting and planning. This analysis enables flexibility and openness in all aspects of the model, including the critical activity allocation process—one of the main differences from other models. The model structure and characteristics could include input from the public and stakeholders in the modeling process. We have successfully applied the model's prototype application and related scenario analysis to a mid-size US metropolitan region. We hope this is a welcome addition to the landuse/transportation planning literature and its further development.

The paper starts with a background discussion and a brief literature review. The next section introduces the Planning Support System (PSS) and the structure that describes our specific PSS, called ELUENT, and a detailed description of each of the five components. Finally, a conclusion summarizes the findings and discusses possible future research

\section{$2 \quad$ Literature and background}

The development of integrated land-use/transportation models has its roots in Lowry's Model of Metropolis (1964). Theoretical and technological advancement within the last few decades has instigated a new wave of study and attention to further developing the models and techniques from various disciplines. As a result, several operational land-use-transportation interaction (LUTI) models have been developed and implemented in real-world situations. A few important reviews of these models exist in the literature. Wegener (1994) reviewed developments in operational integrated land-use transport models and (2004) provided an overview of 20 active urban land-use/transport models that have evolved since Lowry's earlier effort. More recently, Wegener (2014) briefly reviewed selected current operational urban models. De La Barra (2001) also provided a cogent description of large-scale models' evolution and clearly showed how the pieces fit together. Iacono, Levinson, and El-Geneidy (2008) reviewed relevant theoretical frameworks that researchers have used in representing land-use/transportation relationships. Meyer and Miller $(2001,2013)$ provided summary details of these models. Acheampong and Silva (2015) provided a comprehensive review of published research on land- use/transport interaction (LUTI) modeling covering more than half a century.

As examples, METROPILUS, DRAM/EMPAL, and TELUM (Putman, 1983, 2001) are Lowrytype models widely used in US metropolitan areas for the last 30 years. MEPLAN (Abraham \& Hunt, 1999a, 1999b), TRANUS (De La Barra, 2001; Johnston \& De La Barra, 2000), and PECAS (Hunt \& Abraham, 2005, 2007) use the economic input-output model for projections and nested logit models in relation to exchange prices and transport costs. De La Barra (2001) presented a TRANUS application in Swindon, UK, using GIS-related output. Moeckel (2017) generated more realistic results by ensuring 
that no household violates various constraints, including the price of a dwelling, the travel time to work, and the monetary transportation budget.

Alternatively, UPlan, developed by Johnston and Shabazian (2002), is a relatively simple rule-based model developed on a platform of ArcView GIS that allocates urban growth increments in user-specified discrete categories for future years projections. UrbanSim is another popular model developed by Waddell (Waddell, 2002, 2011; Waddell, Ulfarsson, Franklin, \& Lobb, 2007). It is highly disaggregated and can be set up to use parcels, zones, or grid-cells as the primary spatial analysis.

Although a new wave of integrated models has brought significant improvements to the modeling effort, many challenges remain in the modeling process's conceptual and technical aspects. Early on, Batty (1979) called for these types of models to contribute both to science and design (i.e., planning and policy), Berechman and Small (1988) brought the lack of agglomeration consideration in land-use models. Silva and Wu (2012) mentioned the ill-defined and black box nature of some models - as well as limited information and "secrecy involved in some of the modeling strategies" (p. 140)—and ask for more metadata for the models. Referring to several other authors, Silva and Wu explained that some models are either highly abstract to a non-useful degree for policy planning or not yet at an operational level. They concluded that there is still a wide gap between theory and practical applications in some models. We could add to the list the use of unproven theory or lack thereof in some models or model modules, which this paper has tried to avoid.

In other related challenges, Timmermans (2003) questioned the use and applicability of discrete choice models and the random utility theory for spatial choice decisions, such as residential and firm locations. Zoe and Kockelman (2008) showed that discrete choice models do not fit well with related multiple location choice data. Iacono et al. (2008) discussed more points in their extensive review of integrated models and found that most models are still highly aggregated even though they use disaggregated methods. For example, some have used these disaggregated methods in the model structure, but simulation techniques for projections. Additional important points that Iacono et al. mentioned include modest advancements in the four-step transportation-forecasting models, inappropriate use of cellular automata (CA)-type simplistic modeling systems not designed for forecasting, the static nature of almost all models, and the models' large data requirements and resource intensiveness. Finally, we could add the models' over-complexity, spatial distribution-related problems, and missing one or more major regional system components in modeling an urban system to the issues mentioned above.

Sarzynski, Wolman, Glaster, and Hanson (2006) suggested that planners and policymakers should do their best to understand land-use planning's complex nature before making policy changes. While this seems like good advice, Sarzynski et al. did not explain how planners can convey models that calculate so many variables, especially in over-complex or otherwise complicated models. ELUENT, the PSS presented in this paper, attempts to overcome some of these issues by offering an easy to understand model for decision-makers and professional, as well as all necessary essential components and explicit spatial distribution of activities. The PSS also captures the complex nature of the urban system considering the planning and operational purposes behind the efforts. 


\section{The model and the methods}

After a brief introduction, this section starts with a summary of the model and its five sub-models, and we then provide a detailed description of each sub-model. As mentioned, the model improves in a number of ways the operational interaction or integrated models reviewed above:

- The mode is easier to use and is readily understandable by all parties.

- The embedded transport activities and trip generation, distribution, and a potential modechoice in the model help integrate, as opposed to only interact, it with transportation modeling as a real integrated land-use/transportation model.

- It considers economic changes and ecological factors, its ability to include the public and stakeholders' input in the modeling process, and its openness to human interaction distinguish it from others.

Presentations of earlier versions to professional modelers, as well as state, local and regional officials on different occasions, have verified its simple structure, logic, and ease of use.

According to the USDOT (2004), land use and travel behavior interact, and MPOs must work with local governments to thoughtfully develop consistent policies and programs that support metropolitan goals. The model's design allows the public and stakeholders' input in the modeling and forecasting process. This inclusion of stakeholders' input takes the model beyond the conventional integrated land-use/transportation planning models. It makes it a more comprehensive tool to aid decision-makers in policy and planning efforts. Thus, considering the model as a Planning Support System (Anjomani, Shad, \& Saberi, 2005) rather than a model for the combination of sub-models and related processes.

As a significant structural part of the PSS, the planning procedures consider economic development, land use/urban form and structure (see Rodrigue, 2020, for definitions), environmental aspects, and transportation planning in an integrative way (where the region is divided into a grid or zones of small cells). As such, we call the PSS "ELUENT" for its consideration of Economy, Land Use, Environment, and Transportation, among other crucial urban development activities. ${ }^{1}$ It should be noted that ELUENT and its application process are open to inputs from other planning and development activities that institutions and jurisdictions in the metropolitan area are considering or working on for inclusion in a regional plan-making event.

The environmental and land suitability analyzes variant is one of ELUENT's main components. It allows the projection process to be open to human interaction, making it possible to input social and political aspects and decisions into the easy-to-work and easy-to-understand approach. The input could be accomplished by the inclusion and participation of representatives of the decision-making bodies, stakeholders, and the public in various aspects of the modeling process. This inclusiveness would involve a variety of voices in the process from the outset. It would free ELUENT from being like many blackbox models with only inputs and outputs being visible and understandable by the public and even the decision-makers.

ELUENT and its related process consist of a tailored constructed framework as a Planning Support System (PSS). It utilizes all the relevant information that facilitates the analyses and processes institutions necessarily go through when preparing a metropolitan area's plan or demographic forecasts for a variety of planning and policy-making purposes. The open model framework can be tailored to different settings and is useful for comprehensive plan-making, economic development, and policy decisions of all types at the local, city, county, or regional levels. However, this article limits its application primarily to

\footnotetext{
1 Even though the purpose has been to name the PSS based roughly in the order of the significant aspects of the process, we found interesting meanings for "eluent" in relation to the PSS and the modeling and "elution" for the process of modeling of urban regions.
} 
an integrated land-use demographic forecasting transportation model.

The projection sub-model in ELUENT is based on demographic analysis and forecasts of households and employment. The land-use demographic component, ELUENT, like other models, relies on demographic and economic forecasts of total households and jobs for the region. These projections can be obtained from external sources such as the State Demographic Office or internally developed. These total predictions for the region also function as control measures. They need to be allocated spatially in the study area zones to produce the distribution of changes in both households by socioeconomic groups and jobs by their types. ELUENT spatially distributes change in the households in a highresolution zonal level according to various socioeconomic categories as well as types and concentration of employment in the study area. This distribution is performed for each given time interval (e.g., five years) in the forecasting process.

Based on the development literature (e.g., McDonald \& McMillen, 2011), the primary force behind land use and transportation changes is urban development (resulting mostly from economic growth or decline of a region). Therefore, the LUM part of ELUENT's primary purpose is to project economic growth or decline by specific areas of the region, that is represented by employment and household changes in the cells (or land parcels) of a metropolitan region. The results are integrated into the four-step transportation planning process. The initial five-year projection output is used as the base for further analysis and forecast for the next period—as it is also conventional in TDM. In general, ELUENT attempts to project a distribution of economic growth or decline of the region within specific areas, represented by employment and household changes in the metropolitan region's cells or land parcels.

There are five major sub-models in ELUENT (see Figure 1):

- Projection sub-model (i.e., the projection of households and employment data for zones)

- Required land sub-model (calculation of demand for the use of needed land)

- Environmental land suitability (development potential) sub-model

- Allocation sub-model (allocation of households and employment), and

- Trip generating and distributing sub-model, with possible mode choice.

While a few of these sub-models may resemble sub-models in other integrated land-use transportation models or LUTIs, they are different conceptually because ELUENT includes land suitability in the model structure, which affects the sub-models' operations. The model process's unique application through GIS suitability allows for data to be analyzed in smaller zones, such as the $50 \times 50$-meter grids used in the prototype application, or even smaller. These are later aggregated into larger zones as needed, for instance, traffic analysis zones (TAZs), which can be used as inputs for TDM.

Each sub-model requires a specific set of data. The first sub-model uses past and current employment and household data (by job and household type) to project future figures. The second interrelated sub-model uses results from the first sub-model to calculate the required land for each household and employment type in the study area based on land use and density related data. In the third sub-model, ELUENT uses a variant of environmental and land-use suitability analysis through GIS technology to consider both natural environmental factors (e.g., the presence of wetlands, water bodies, and other environmentally sensitive areas) and built environmental factors as drivers of land-use changes. It uses suitability ratings and weightings mostly based on proximity/accessibility variables (e.g., time/distance to major highways and major activity centers) to provide "development potential" indices for different uses in each of the zones. The fourth sub-model distributes and allocates projections for different types of jobs and households of different socioeconomic groups into study area zones or cells based on the indices of land-use development potentials (developed in the third sub-model). If desired, the results can then be aggregated into the TAZs, providing figures for various employment types and different 
household socioeconomic categories that can, in turn, be input for the TDM.

For this sub-model, ELUENT offers two choices and suggests one for the region's core area and the other for the surrounding area. The latter uses the development potentials from the third sub-model in the variant of the traditional land suitability analysis developed for ELUENT. This is the alternative presented in this paper. The other choice is the multinomial logit (MNL) (Ben-Akiva \& Lerman, 1985; Wooldridge, 2013), which also uses suitability measures within zonal levels. While the suitability allocation variant can provide more normative results by including stakeholders and other related input during the analysis process, MNL represents a traditional positivist approach, considering land-use changes in the prior period to forecast changes in the next period. The suitability analysis is more appropriate for planning the development of the lesser developed areas, such as the growing fringe and undeveloped areas. The MNL version is thought to be more suitable for capturing ongoing trends in the built-out core and the region's developed areas. This paper presents the suitability-based application for the analysis of development potentials in the study area cells in undeveloped areas of a metropolitan region.

Finally, the fifth sub-model, proposed at a conceptual level, attempts to inventory the additional trips generated in micro-level in small cells as a result of growth (or decline) and organize them into an origin-destination table (representing work-to-home and non-work trip data, respectively). The results improve the trip distribution forecasting phase of the four-step transportation planning process. Since the additional trips are at the micro-level, a mode-choice consideration might also be possible.

Figure 1 presents how the five sub-models are connected in ELUENT and their connection to the four-step transportation model. The following sections describe these sub-models in more detail.

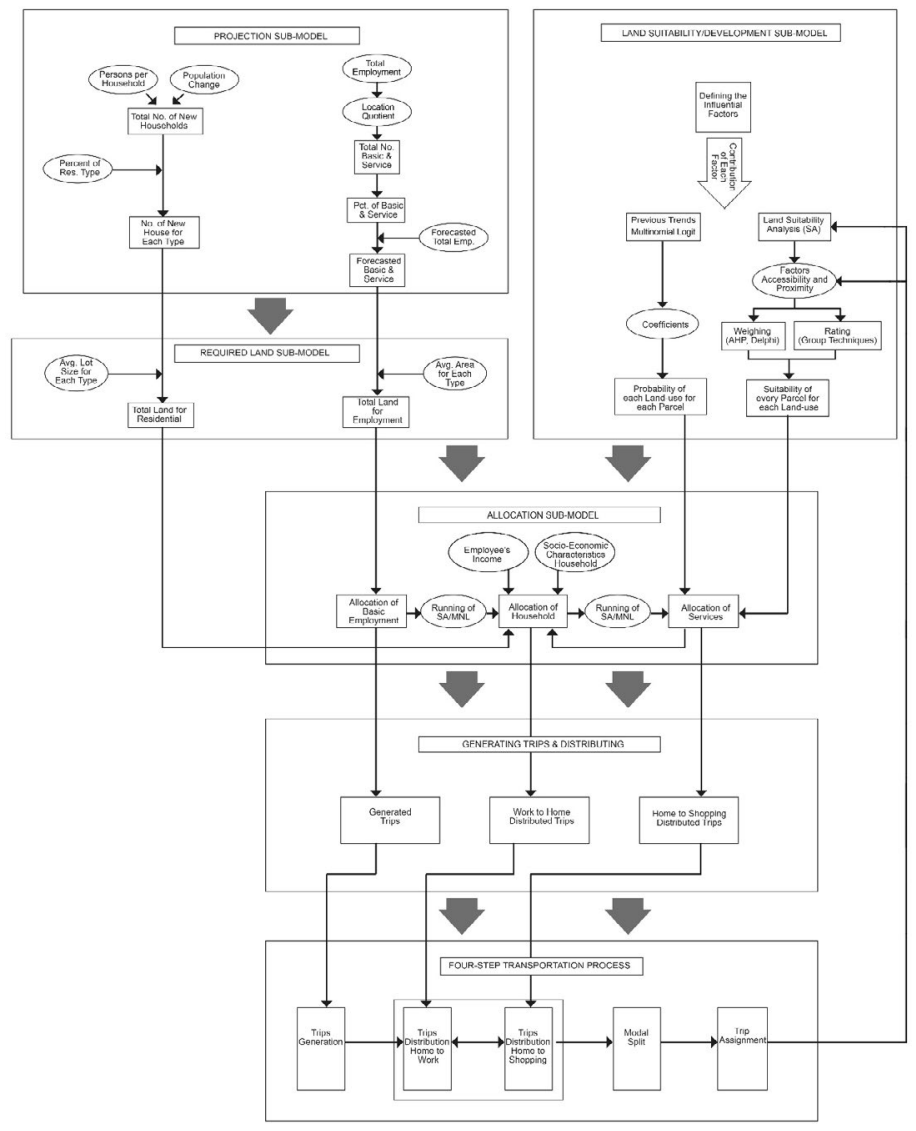

Figure 1. Flowchart of ELUENT presenting the sub-models and process 


\subsection{Projection sub-model}

ELUENT attempts to project a distribution of economic growth and decline of the region within specific cells of the study area (i.e., employment and household changes in the cells or parcels). There are only a few theoretically sound, practical, and operational models for the projection of a region's economic growth/decline (Hartshorn, 1992; McDonald \& McMillen, 2011). Some ILUT or LUTI models of Lowry type (e.g., DRAM/EPAL, Putman 1983 \& 2001; or TRANUS, De La Barra 2001; Johnston \& De La Barra, 2000) use the economic base model (Klosterman, 1990; McDonald \& McMillen, 2011; Wang \& Von Hofe, 2007) for this purpose. PECAS (Hunt \& Abraham, 2005, 2007) and MEPLAN (Abraham \& Hunt, 1999a, 1999b) use economic input-output models (Wang \& Von Hofe, 2007; McDonald \& McMillen, 2011). The economic base model is ELUENT's economic engine. The economic base theory is the core concept utilized in this research for predictions and later in the allocation process in unique conjunction with the suitability results.

The economic base theory deals with regional development and predicts growth or decline in a region's economic activity. In general, the economy is divided into two sectors, basic and service. The basic industry produces goods that are mainly consumed outside the region, and the service sector supports basic industries and serves the region. The economic base model uses basic employment to project the first round of household changes, which in turn produces projected changes in the first round of service employment; the process then continues until all jobs and households are projected. This projection process can be depicted below, which shows how the economic base model projects population and service employees from the change in basic employment.

$\Delta \mathrm{E} \rightarrow \Delta \mathrm{P} 1 \rightarrow \Delta \mathrm{S} 1 \rightarrow \Delta \mathrm{P} 2 \rightarrow \Delta \mathrm{S} 2 \rightarrow \Delta \mathrm{P} 3 \rightarrow \Delta \mathrm{S} 3$

Where:

$\Delta \mathrm{E}$ Basic Employment Change,

$\Delta \mathrm{P}$ Population Change

$\Delta \mathrm{S}$ Service Employment Change

There are several methods to identify which industries fall into the basic or service sectors. ELUENT uses the location quotients technique, which is the most commonly utilized economic-based analysis method for dividing employment into basic and service sectors in each economic sector. It does so by relating an industry's local employment share to its larger reference region, such as its state or national employment share (Wang \& Von Hofe, 2007; Klosterman, 1990). Equation 1 computes location quotients by dividing an industry's share of the region's employment by the industry's share of jobs in the state.

$L Q_{i}^{t}=\frac{e_{i}^{t} / e_{T}^{t}}{E_{i}^{t} / E_{T}^{t}}$,

Where:

$L Q_{i}^{t}$ Location quotient for industry $i$ in time $t$,

$e_{i}^{t}$ The study area employment in industry $i$ in time $t$,

$e_{T}^{t}$ The total employment in the study area in year $t$

$E_{i}^{t}$ The State employment in industry $i$, and

$E_{T}^{t}$ Total State employment in time $t$ 
The essential requirements of a land-use model for integration with a TDM are the employment and household projections for the study area's zones or cells. A land-use model relies on demographic and economic data (e.g., population and employment totals for the region). Such employment and population totals for the region are exogenous to the model and need to be allocated spatially in the study region's cells or zones. These totals also act as control measures to check that the sum of projections from the model for all the study regions' cells does not exceed the control totals.

The Projection or Development sub-model prepares the households and employment data by socioeconomic status (e.g., income) and employment types in the two and four-digit North American Industry Classification System (NAICS), both for the base year and the projected year, and makes them ready for the other sub-"models" use. The required data include the following:

- total population, household income, and total employment for the base year and the six projected intervals (5-year periods)

- number of households and employees per area (density)

The projections of jobs and household data are derived from the two to four-digit NAICS employment types and US Census household income categories.

First, concerning employment, the base year total employment data for the study area is collected in two to four-digit NAICS that included economic sectors. In Texas, this data is available from the Workforce Commission. Next, this employment data needs to be broken down to basic and service data. Equation 1 is used to calculate the number of basic and service sector employment for the study area. Using the location quotients technique, employment data for the study area are compared with the larger reference area's employment data (the State of Texas in our example) to identify which industries could be categorized as basic and service sectors. The results most often are needed to be consolidated to two-digit level NAICS, which makes more sense and is more manageable for land use planning purposes that do not have many categories compared to four-digit NAICS. For example, this step resulted in 17 categories out of two-digit NAICS employment data in the application example. This data is converted to percentages for later use with the projected data to break down total projected employment data into NAICS categories for each projection period.

Regarding household projections, the total number of households for different socioeconomic groups, such as income and education for the study area for the base year, needs to be determined from available data sources. Such categorization of households is required for input into TDM. As discussed above, total household forecasts for the projected years are necessary as a control measure akin to employment totals. The number of socioeconomic groups and housing type categories will be decided based on the desired level of the details and resource availability. To keep the process simple in the prototype application, household data for the base and projection intervals are divided into low, medium, and high-income categories. These were allocated into single-family (SF) and multifamily (MF) housing. However, more socioeconomic groups and housing categories could be used for household projections in full applications.

In summary, the economic base theory drives the development process in the model, acting as ELUENT's growth/decline engine. ELUENT uses the location quotient technique to split the projected two- to four-digit NAICS employment data (based on the available data) into basic and service categories. The employment and household projections are then used in the other sub-models, as explained below. 


\subsection{Required land calculation sub-model}

The required land is defined as the quantity of land needed (e.g., an acre or square feet) to accommodate households and jobs' future growth. The previous sub-model forecasted the total number of households in different socioeconomic categories and the basic service employment of different NAICS groups. Since the allocation sub-model in ELUENT will attempt to locate the projected households and jobs in the study area zones, there is a need to calculate the amount of land needed for each of their respective categories based on acceptable density assumptions. The required data included the following:

- average parcel size for each household income (required land)

- average area per worker (required land)

The calculation of required land starts with obtaining the existing residential and non-residential land area and estimating their growth between the base and future years. This can be achieved by reviewing the base-year parcel data and then merely computing the percentage, or ratio, of the acreage used for different housing types, e.g., single-family (SF) and various multifamily (MF). The non-residential required land is calculated by multiplying the average employment per area in the base year with the projected number of jobs (employment) in every two- to four-digit NAICS category.

Finally, the "average area per employee" needs to be calculated to identify the quantity of land required for the projected employment. The sub-model uses the calculated average land area required per employee and total land area data for each projected employment type to determine the required land area (Equation 2). Since the difference between the number of jobs for the base year and the projected year is calculated for both the basic and the service sectors in the projection sub-model, multiplying the difference by the average area per number of jobs, the required land areas will be found (Equation 3).

$$
\begin{aligned}
& A A E_{i}=L A_{i} / E_{i t 1} \\
& R L_{i t 1}=E_{i t 2}-E_{i t 1} * A A E_{i t 1}
\end{aligned}
$$

Where

- $A A E_{i t 1}$ is average area per employment in industry $i$ at time $t_{1}$

- $L A_{i t 1}$ is Existing land area used for industry $i$ at time $t_{1}$

- $E_{i t 1}$ is number of employees for industry $i$ at time $t_{1}$

- $R_{\text {Lit } 1}$ is Required Land for Employees $i$ at time $t_{1}$

- $E_{i t 1}$ is number of employees $i$ at time $t_{1}$

We employ regression analysis to calculate the required land area for single-family or multifamily housing types based on the number of households in each income category. The regressions establish the correlation between total square feet of land area for single-family and different types of multifamily housing units as dependent variables and location contributing explanatory variables. The variables could include socioeconomic variables using theoretical and empirical literature as a base. They could consist of median income, education, percent minority, etc. and spatial and activity-related variables, including proximity to highways and intersections, downtowns and major activity centers, proportions of existing land uses of block groups in the same area, etc. Equation 4 represents the general form of the regression equations.

$Y=\alpha+\beta_{1} X_{1}+\beta_{2} X_{2}+\varepsilon$ 
Where:

- $Y$ is the dependent variable (e.g., total square feet of land area for single-family);

- $X_{1}$ is a vector of socioeconomic explanatory variables;

- $X_{2}$ is a vector of spatial and activity related explanatory variables; and

- $\varepsilon$ is the error term.

Using the results, the required land area is estimated for single and different multifamily households. GIS parcel-level data, including parcel size and categories of use for the study area, can help to calculate the necessary data and results. As an example, the County Tax Assessor data was relied on for the prototype application.

Finally, the "average area per employee" needs to be calculated to identify the quantity of land required for the projected employment. The required land area can be determined using the calculated average land area required per employee, as well as total land area data for each type of projected employment. A use matrix (Freilich \& White, 2008) can be utilized as a reference to convert employment activities into land-use categories. This task requires a more detailed description of employment categories at the three-digit or more NAICS level to determine specific activities in metropolitan-level land-use development scenarios.

\subsection{Environmental/land suitability (development potential) sub-model}

The use of suitability analysis in LUTI was first introduced and implemented in transportation research reports (Anjomani, Tayebi, Nostikasari, \& Kharel, 2010; Kockelman et al., 2008; Kockelman et al., 2011). ELUENT uses a modified version of environmental and land suitability analysis developed for the research to produce "development potential" scores for each land-use category in each cell to help allocate activities in the next stage, the allocation sub-model. This method measures the contribution of different factors and the formation of the relationships between the variables and the land-use change to derive development potentials.

In general, suitability analysis (SA) is used to identify the most suitable places for locating future developments for each land use by considering all significant factors affecting suitability. Early studies land suitability analysis has been used since the beginning of the twentieth century but attracted more interest after the publication of Design with Nature by McHarg in 1969. He provided an organized version and a theoretical basis for the technique, which involves considering land resources and the ecologically sensitive land allocation in planning (McHarg, 1969, 1992). However, with the advent of GIS, this technique has evolved and has been integrated into existing GIS platforms. Johnston and Shabazian (2002) developed the UPlan Urban Growth Model as a rule-based suitability GIS model for analysis at a regional level. Their model allows the user to input expectations in demand, uses population and employment projections, other information on essential features, and user-defined constraints for development to forecast future land-use patterns. As was mentioned, a variant of the GIS land suitability analysis has been developed for ELUENT. It is being used as the central part of the process, facilitating connecting different sub-models in ELUENT. The tools in ArcGIS enabled the factors in the study to be represented and analyzed simultaneously to produce suitability, or in our version, development potential scores for all land uses.

The method measures each land parcel's "development potential" for a land-use directly by determining and assigning "rates" as measurements for the factors and the "weights" to measure the factors' contribution to the land's suitability for that development. Anjomani (1984) proposed functional form for the suitability, $S$, of a location $i$ for land use $j$ (or $S i j$ ), which in linear form could be represented as: 
$S_{i j}=b_{1} F_{1 i j}+b_{2} F_{2 i j}+b_{3} F_{3 i j}+\ldots+b_{k} F_{k i j}$

or

$S_{i j}=\sum_{k} b_{k} F_{k i j}$

Where $F$ s are factors or variables selected based on the theoretical and empirical literature. Their scores measure ratings of each factor's suitability according to the degree of its effects-positive or negativeon each of the selected land uses $j$, in locations $i$. b's are coefficient measuring importance (weight) of the $k$ chosen factors.

Suitability scores for each land use and location, $S_{i j}$ 's, can then be calculated by multiplying coefficients and their associated factor scores. They are summed up, as shown in Equations 5 and 6 above. Suitability scores are computed for all zones and all developments or land uses under consideration. The Delphi technique (Lindstone \& Turoff, 1977; Taleai \& Mansourian, 2008) or a multi-criteria evaluation technique — such as Analytical Hierarchy Process (AHP) (Banai, 2010; Saaty, 1980, 1994) or Analytic Network Process (ANP) (Zebardast, 2013)—can be used for determining factor weights.

Developing a realistic land-use change model first requires identifying the most critical factors that drive changes and then representing these factors in the model (Veldkamp \& Lambin, 2001). Identification of these factors is an essential step because they presumably drive changes in urban development. In the land suitability development (potential analysis) developed for ELUENT, we need to select natural and built environmental factors that affect growth or decline. Therefore, the factors considered are divided into two categories:

- natural environmental factors

- built environmental factors

Their related suitability scores for different land uses are mostly related to proximity (areal or Euclidian distance) for natural environmental factors, and proximity and accessibility (network-based time and distance), and their attraction measure for built environmental factors. Use of time and distancerelated variables in relation to land use, transportation, and, in general, urban and spatial modeling have a long history that goes back to more than a century ago as attempts were made to use Newtonian Physics social science applications. The evolution of this usage and its different developed concepts and variants under the gravity model's umbrella has been widely reviewed in the literature (cf. Haynes \& Fotheringham, 1984; Meyer \& Miller, 2013). Related concepts and formulations in connection to this research are Hansen's (1959) development potential concept and formulation, Lowry's (1964) contrived combination of gravity model and economic base theory, and Wilson's (1970) theory of gravity model using the entropy-maximizing principle and elegant formulation for the model.

The selection of the suitability factors is based on related theoretical and empirical literature (e.g., Berke, Godschalk, Kaiser, \& Rodriquez, 2006; Marsh 2010; McHarg 1992). It depends on the characteristics of the planning area and development or land-use categories being considered. Natural environmental factors help to determine the development suitability of a location for land use. Due to safety and environmental concerns, several natural ecological factors, such as the degree of slope, floodplains, proximity to water and green pasture features, and sensitive habitats, prohibit development. Similarly, built environmental factors are used to determine the development potential of a location for each development type (land use) under consideration. For the built environment, considering social, economic, and political aspects, the factors typically include activity areas as attractors, such as employment centers, airports, highways, major roads intersections, shopping or other urban centers, and existing land uses. 
Detractors include crime-infested areas, excessive noise regions, environmentally sensitive or polluted areas, etc. It is interesting to mention that land close to some of the natural environmental factors such as water is often very attractive for developers because people have a high willingness to pay for it and is a factor that attracts development.

Because the natural and built environmental factors affect development, they need to be assessed as drivers contributing to land-use changes. This involves the rating process in the suitability analysis, whereby the extent to which each suitability factor affects each selected land use determines the value of its rating. The physical, socio-economical, or environmental characteristics of the planning area provide the basis for rating assumptions in the rating process (e.g., proximity to a crime-infested area). As with any other modeling efforts, there are several assumptions in different land and environmental suitability analysis stages. While proximity and accessibility (network-based) and related attraction measure (e.g., via a gravity model output) provide base data for ratings, assumptions are still needed in different stages to complete the factors' scores. As an example of assumptions for ratings, we could mention higher ratings for areas closer to water features or major highways and roads because of infrastructure accessibility and availability. Commercial rating is higher near major highways and would be excluded for areas further away from major roads. Considerations of low and high slopes are also similar because of their implications for site preparations. In terms of natural environmental factors, special attention is given to locations near water features and green spaces to protect them, as discussed above (for more discussion of assumption, see Berke et al., 2006; Klosterman et al., 2018; Marsh, 2010; and McHarg, 1992).

The factors for every land-use are then weighted according to the importance of each factor against the others. There will be similar assumptions in the weighting process (e.g., assigning lowest weights to the distance to the water feature to detract development in close proximities, and highest weights for distance to major roads and highways in commercial land uses (Klosterman et al., 2018)). After the rating and weighting process, values are combined for each development type (i.e., land use); the result provides development potential data as the input for the allocation sub-model for the determination of the locations.

It should be noted that the described processes for rating and weighting use group techniques, Delphi, and AHP to provide the "development potential" scores for the cells (discussed above). These are performed by the modeling and planning group collectively through meetings, discussions, communications, and human interactions (instead of a black-box computer model). Thus, the process is open to scrutiny and input from the public, stakeholders, and experts with local sensibilities and knowledge of current development events and trends. Regular meetings of representatives from these concerned groups and the jurisdictions with the planning-modeling managers that starting early in the process and continuing to the end would facilitate avoiding future problems to achieve better results. Such issues and problems usually arise between different jurisdictions and MPO regarding the projection results and plans for the region's perceived development. Inclusion of public and stakeholders and involving their experts in ratings and weightings through group techniques, Delphi and AHP in deriving development potentials at this stage, as well as, and more importantly, the allocation process below, would help to avoid the later issues and disagreements.

\subsection{The allocation sub-model}

The ELUENT allocation sub-model aims to use all data and results produced in the above sub-models to generate a final composite result for employment and household locations considering all jurisdictions and government agencies' plans and policies. Using the development potential scores developed in the environmental and land-use suitability analysis stage, ELUENT allows two general ways to allocate activities to their appropriate locations. As previously mentioned, one way to measure the decision in- 
volved in locating or developing land parcels with different attributes and features is multinomial logit (MNL) (see, for example, Ben-Akiva \& Lerman, 1985; Wooldridge, 2013). The MNL version could capture changes occurring in the built-out core and the region's developed areas to capture ongoing trends using the previous period development data for trend extrapolation. The other way is a variant of land suitability analysis and the allocation process described in this research. It provides results that are more normative because of the nature of its allocation process. More importantly, this method could involve stakeholders, decision-makers, and public choice considerations in the process, which can be achieved by having their representatives participate in the ongoing process from the inception until the end (usually a three- or five-year period). This method is also more suitable for modeling the development of undeveloped areas, in part because it has been developed for the analysis of land development, to begin with, and it has gone through an evolutionary process since the early last century (Anjomani, 1984; Collins, Steiner, \& Rushman, 2001; Hopkins, 1977; Klosterman et al., 2018; Malczewski, 2004; McHarg, 1992).

Both choices use suitability ratings of the factors for the study area's zones based on their attraction extent and proximity/accessibility akin to the gravity model principles. The factors include major activity centers, land, and environmental-related factors, including environmentally sensitive areas. While ELUENT could use either of the methods for a metropolitan area in the allocation process, a combined two-tier analysis of developed and less developed areas of the region with these two approaches seems to be the most appropriate. This paper will continue to focus more on the suitability-based application to analyze land development changes in a metropolitan region's undeveloped areas.

As part of this sub-model, the employment categories are aggregated into a smaller number of groups suitable for land-use allocation. The compatible retail, restaurant, hotel, and recreation-type activities may be aggregated into one group for allocation purposes since they usually will be in the same activity area, particularly in downtowns, mixed-use centers, and major activity centers. On the other hand, developable land is defined as the amount of land on which additional and new development can occur within the environmentally sensitive areas' constraints and per local plan and policy (Berke et al., 2006). Thus, the allocation of the projected employment and household data into the developable land (supply) is based on how much the required land (demand) is needed to accommodate them.

The allocation process involves determining the order of assigning activities into the most suitable and highest potential developable land in the region. Since ELUENT essentially allocates projected employment and household growth, the allocation order (and in the prototype application) is based on the well-known Lowry model (1964), which distributes activities based on the economic base theory. Another alternative is the use of bid rent theory (Alonso, 1964), which is based on the utility or price and demand for real estate changes as the distance towards the activity centers increases and the willingness to pay measures. However, the ELUENT suitability sub-model uses time-distance from the activity locations and town centers in the rating and weighting stage; therefore, the "development potential" measures have already indirectly included the utility for distance changes. In a sense, our method is using the combination of these two well-known approaches. Activities that benefit more from accessibility and are less land-intensive will outbid activities that do not depend as much on accessibility and are more land-intensive. While basic industries are important drivers of the local economy, they are sometimes located less centrally, where land prices are lower and larger tracts of land may be acquired. ${ }^{2}$ However, such basic industries most often instigate Lowry-type ripple effects in the economy and, as a result, also

\footnotetext{
2 A truncated version of this process akin to the Garin-Lowry formulation (Garin, 1966) is possible and is explored by the author.
} 
in the urban structure-given a few years for effects of taking place. An excellent example of such a development is Toyota's move to the Dallas area from Los Angeles.

Furthermore, some basic firms prefer to relocate to high-rises in major urban centers or proximity to them, so their effects on land-use distribution on today's economy should not be ignored. In the same vein, service businesses, although driven by the presence of residential land-uses, are usually willing to pay more per square foot than residential uses for desirable locations. The suitability stage in ELUENT allows consideration of all these different measures along with the inclusion of local knowledge of stakeholders, the public, and their expert representatives, and bringing them in one place in the process.

The projected employment and households' distribution begins by distributing the basic jobs to their most suitable locations with the highest development potentials, using the "development potentials" from the previous stage. This first allocation is a crucial step because all the remaining distributions will be affected by it. If we consider the fact that the distribution of jobs and households is the primary input into the transportation planning process, this step's significance becomes even more evident. This initial step has not been much discussed in the LUTI literature. It is either missing or is not clearly addressed in some of the integrated operational models, particularly the Lowry-type models such as DRAM/EMPAL or TELUM (Putman, 1983, 2001).

This beginning step, and the rest of the allocation process, also allows the need to bring publicprivate stakeholders and decision-makers into the process, which started early on. As was discussed before, ELUENT enables the involvement of expert representatives of the jurisdictions and stakeholders through regularly scheduled meetings with planning-modeling managers from the process's early steps. These representatives would bring to the plate local sensibilities and knowledge of current development events and trends, which would help realign the process in the right direction, especially in the model's allocation stage. The collaborative group would scrutinize the allocation result and its visualization via GIS presented on the metropolitan setting's maps. If needed, reruns or adjustments would be made to include the new developments or resolve perceived equity or misallocations problems. The collaborative process would continue until the final socially and economically sound results to be achieved

The allocation process first distributes basic employment to the most suitable locations with the highest development potentials' scores using the prior sub-models' information. After all these key jobs are allocated to their appropriate places in the study area, the suitability or development potential scores prepared in the previous sub-model need to be updated to take account of these newly added and distributed employments. Next, the employees need to be matched to their appropriate household socioeconomic groups (e.g., income) to prepare them for distribution to their residential areas. This is done through a table that matches the percentages or numbers of employees' wage intervals by their respective households' income intervals.

Next, employees are allocated to their most likely residences based on "development potential" scores produced and updated in the earlier sub-models. A calibrated home-to-work attraction-constrained gravity model (Wilson, 1970, Wegener, 2014) will be used in this step, as is discussed in the next sub-model. A calibrated gravity model may not be available in some medium-size or smaller metropolitan areas. For those cases, the model could use the GIS buffering techniques by considering the distance decay function as part of its GIS operations. Adjusting the employee figures to their respective household figures would allocating the first wave of household growth (households related to the basic employment) to their appropriate residential locations.

Next, to fulfill this first household group's service needs, the respective service employment is allocated in the study area based on the development potential scores produced earlier and aid of a calibrated retail or non-work gravity model (Lowry, 1964; Wegener, 2014). GIS buffering technique, as mentioned above, connecting households to service employment locations could help if the gravity model is not available. This would allocate the first wave of required service employment to their appropriate 
location in relation to the first wave of household locations, albeit considering their socioeconomic characteristics.

Service employees will also be distributed to their likely residential location in either single-family or multifamily housing categories, based on development potential scores and a home-to-work gravity model or the GIS buffering techniques like the previous stage allocating employees to their residences. To derive more accurate projections in each of these steps, there is a need to update the development potential scores because of the new allocation in the previous step. This is because a new set of attractors has been added to the region. This process continues until all jobs and households are allocated accordingly. ${ }^{3}$ Combining the figures for each type of employment or household category for each cell will provide the total number of jobs and households with their types for each cell. The results will then be aggregated into the TAZs, producing figures of various employment types and household categories as inputs for a TDM.

\subsection{Generating and distributing trips sub-model}

As can be discerned from the previous section's distribution discussion, the ELUENT's allocation procedure uses two single-constraint gravity-type spatial interaction models akin to Equations 7 and 8 (Lowry 1964, Wegener 2014). These models distribute the newly generated employees to their residences and service employees to their job locations based on households' shopping (non-work) trip.

$$
\begin{gathered}
T_{i j}=\frac{R_{i} \exp \left(-\beta c_{i j}\right)}{\sum_{i} R_{i} \exp \left(-\beta c_{i j}\right)} E_{j} \\
S_{i j}=\frac{W_{j} \exp \left(-\beta c_{i j}\right)}{\sum_{i} W_{j} \exp \left(-\beta c_{i j}\right)} P_{i}
\end{gathered}
$$

Where:

- $T_{i j}=$ Work trip from $i$ to work zone $j$,

- $R_{i}=$ Households in $i$,

- $c_{i j}=$ Travel time between $i$ and $j$,

- $E_{j}=$ Employees in $j$,

- $S_{i j}=$ Shopping trips between residential zone $i$ to retail zone $j$,

- $W_{j}=$ Shopping facilities in $j$, and

- $P_{i}=$ Population in $i$ to be distributed.

This process starts with the ruled-based distribution of the generated basic jobs to their appropriate small cells. It then uses the home-to-work gravity model to distribute them to residences in a disaggregated manner. This step is followed up with a similar process sequentially distributing residences to their related service areas, producing work to home and home to shopping trips at micro-level, respectively (See Figure 1). These additional trip data could be inventoried into an origin-destination table or into the work-to-home trip matrix to update the existing home-to-work trip data. Similarly, the trip submodel would inventory home to service trip data to the related trip table. Thus, forecasting the trip

\footnotetext{
3 For this point, I am indebted to the valuable comments provided by one of the anonymous reviewers. Appreciating these valuable points from this reviewer, I used them throughout the rest of this paragraph.
} 
distribution for the transportation study area at the micro-level as an endogenous part of the ELUENT's demographic and land-use forecasting process. ELUENT's approach and design contrast to most LUTI models that do not have such an integral part for trip generation and simply interact with the transportation four-step model. In a sense, what this sub-model accomplishes is usually conducted in the first three steps of the four-step transportation planning process (i.e., trip generation, trip distribution, and mode-choice models in the four-step model).

Similarly, in distributing households to their service needs, ELUENT could update the service or non-work trips table and produce the related trip forecasting inside this integrated land-use/transportation model. It might be unnecessary to take the aggregated TAZ figures of the PSS as an input to run those steps in TDM because these steps seemingly have already been implemented inside the PSS. This generation of trip data in ELUENT provides a more integrated way than the usual practice of inputting the LUM results into the TDM in the land-use transportation interaction (LUTI) modeling. Most operational models such as DRAM/EMPAL- ITLUP-TELUM (Putman 1983, 2001), MEPLAN (Abraham \& Hunt, 1999a, 1999b) UrbanSim (Waddell et al. 2007; Waddell 2002, 2011) use interaction between land-use and transportation models, connecting the two models through a feedback loop. In contrast, trips occur at the micro-level inside ELUENT, similar to the way they happen in the real world, which constitutes a more natural way of modeling land-use transportation relations for forecasting purposes. However, for a variety of other considerations, such as further dealing with congestion, it might still make sense to input the results into the four-step TDM and iterative feedback from it into ELUENT, which would improve the outcomes for both (See Figure 1). We believe this constitutes a real and better integration in the land-use/transportation forecasting process.

Finally, because ELUENT provides the land use and trip data at a micro-level, the data could be taken to aid in performing the third step of the TDM, discrete choice logistic mode-choice estimation. This consideration of mode choice would result in further integration of land-use and transportation modeling in ELUENT. An Iterative Proportional Fitting (IPF) procedure might help derive the needed micro-level data. This addition to the model would allow the consideration of the public transit trips in ELUENT, which would enhance its capability further. However, more research is needed on these aspects as part of the future developmental work on the PSS and ELUENT.

\section{$4 \quad$ Prototype application}

As was mentioned above, a prototype model application of an earlier version was developed to test the model. The Austin region was selected as the study area because of the availability of demographic and geospatial data needed for the prototype application. As Texas's capital, the study area is a mid-size urban region with a population of over two million, which has seen a rapid and sustained job and population growth.

The implementation process allowed for fine-tuning the process and made it possible to present an executed example. The prototype application was intentionally kept relatively simple so that it would be easy to understand and follow. Its brief description will help clarify the discussions in the previous sections. The model application spatially allocated all projected employment types and household categories across the undeveloped 50 by 50-meters grid cells in a five-year time-intervals, 2005 to 2010, for the study area, which can be depicted as a composite land-use map with the aid of GIS for visualizing the results. Figure 2 compares the projected results to the actual land-use changes for Austin's city for the application period to show the reliability of the model's projection ability. The results were later aggregated to TAZs, as inputs for TDM. 

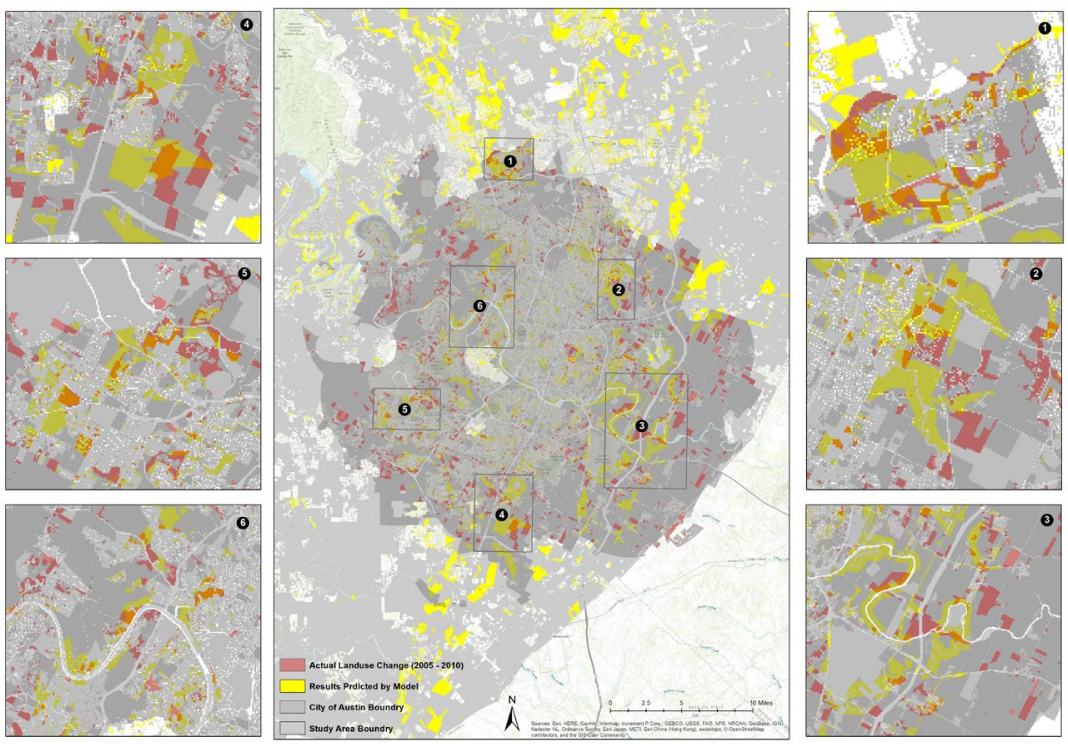

Figure 2. Actual land-use changes vs. model results

Scenarios were applied to check the effects of different policy decisions on land-use patterns and to test the validity and accuracy level of ELUENT's forecasting ability. The earlier version of ELUENT was run for two different scenarios: 1) projecting the land-use effects with State Highway (SH) 130, and 2) the land-use effects without SH 130. Comparing these two scenarios estimated the impact of the building (or not building) the new highway in the Austin region and the shifts (losses and gains) of development across the study area.

The results showed the different distributions of employment and households without and with $\mathrm{SH} 130$, respectively. In general, developments were more distributed around and along with the SH 130 than the scenario without the highway. A cursory comparison of the projections with the region's real-world development several years after developing SH 130 allowed to verify further the reliability of ELUENT's projection ability by the supporting agency representatives, who lived and worked in the region and were familiar with changes.

\section{Conclusions}

The PSS presented in this study introduced the ELUENT and its internal structure. It was followed by a description of the five significant sub-models that included job and household projections, required land calculation, land suitability development "development potential," activity allocation, and generating and distributing trips sub-models. The trips sub-model, which is embedded inside PSA, allows trip distribution activities (and possibly mode-choice) to be uniquely forecasted inside ELUENT. The results fed into the transportation planning process, and it could receive and use information from TDM. The paper also briefly introduced its successful prototype application results for a medium-sized growing metropolitan area, Austin, Texas. The sub-models are necessary to project employment and household data by type, calculate the required land, assess various cells' development potential, and spatially allocate newly added jobs and households.

The use of a developed variant of GIS suitability analysis in ELUENT and its structure and the analysis process's openness allows input from stakeholders and decision-makers during the process. Such 
information is critical in the allocation process, which helps to achieve results in line with stakeholders' development perceptions, local economic activities, and jurisdictional plans and visions. In the suitability stage, this input helps the derivation of development potentials and in the allocation process. More importantly, it permits the distribution of the projected employment and households to their most appropriate locations. The allocation begins by distributing the basic jobs to their most suitable locations with the highest development potentials. This beginning step is crucial because of its ripple effects in everything else, including the final land uses and even the results of four-step transportation planning efforts. This significant step in ELUENT is explicit and not left to the closed black-box technical analysis like some of the land-use models

A significant point and opportunity in the allocation step are to involve the stakeholders, public and private parties, decision-makers, and local expert representatives to elicit their input and intimate local knowledge in this critical step and continue during the allocation process. This is possible in ELUENT because of its open structure, contrive use of land suitability/potential analysis, and economic base framework, and the other model attributes. Through this involvement, the stakeholders' views and reflections are part of the process from the outset, and it is more so during the allocation process. Therefore, there are no surprises when the projection results become public. Usually, issues and disagreements arise between jurisdictions and regional planning agencies over the region's perceived future growth decline and MPO projections. The inclusion of the public and stakeholders in the process is new and may need more research on social and political aspects. Therefore, these different approaches and integration of stakeholders' representatives with local knowledge should be pursued through guidance from planning and social science literature and theories (e.g., Friedmann 1973; Forester, 1999; Innes, 1995) in future research and applications of ELUENT.

A prototype application of the earlier version with a related scenario analysis results appeared to support the projection ability and reliability as an integrated land-use/transportation model for metropolitan analysis and planning. A few presentations of an earlier version of ELUENT to professional modelers and local and regional officials have verified that its simple structure, logic, and use of established theories are readily understandable. Like many other models, ELUENT is always progressing and evolving. ${ }^{4}$ The promising results of its prototype application to Austin, Texas, and the scenario analysis also demonstrated how this new system overcame some of the most common shortcomings associated with some existing models. These included consideration of effects of future developments on the environment, easy to understand for decision-makers and the public, and ease of use via GIS functionality and suitability analysis for estimation of development potentials. The further Improvements in ELUENT attempted to better model metropolitan economic systems using NAICS combinations for land-uses, input from stakeholders, and better integration with the transportation modeling process, as described above.

The development of ELUENT, the sub-models, and its related processes are ongoing. Further research would help to validate and develop the model theoretically and empirically with attention to its applicability to the different size regions and the use of smaller cells for applications. However, more critical research would be directed to examining more complex transportation-related environments, as well as major urban policy options and predicting their effects on planning and policy analysis. As an example, this would include consideration of congestion, trip volume, and environmental aspects in the

\footnotetext{
4 The model has already gone beyond its exposition in this paper, as will be hopefully documented in future upcoming articles.
} 
transportation module and its connections to other sub-models. Similarly, the perceived mode-choice addition and public transit effects on land-use need further research and development. The results would help decision-makers with critical alternative actions in today's sensitive and challenging circumstances. Relevant urban policy alternatives related to the three pillars of sustainability, including economics, the environment, and equity, along with the newly added dimension of livability (Berke et al., 2006; Godschalk, 2007), could be examined with ELUENT and its processes. The flexibility and open structure of ELUENT and its GIS-based suitability analysis (development potential) module developed for the PSS provides inherent possibilities for interaction with the PSS. A variety of policy alternatives or inputs from the public and other stakeholders could be entered into the analysis process model. Related efforts need to be undertaken to explore the flexibility of the model in handling variations and changes in urban structure, growth decline of centers, and some of the general weaknesses of the models that were discussed in the introductory part of the article. Further research is needed to overcome the present limitations and evaluate possible potentials of the model, some of which were discussed in this article.

\section{Acknowledgments}

The author would like to acknowledge the generous support of the Texas Department of Transportation through Project 0-5667 that has made this research possible. The author also would like to thank his colleague Professor Kara Kockelman for her continuous support and constructive comments throughout this research process. 


\section{References}

Abraham, J. E., \& Hunt, J. D. (1999a). Firm location in the MEPLAN model of Sacramento. Transportation Research Record, 1685, 187-198.

Abraham, J. E., \& Hunt, J. D. (1999b). Policy analysis using the Sacramento MEPLAN land-use/transportation interaction model. Transportation Research Record, 1685, 199-208.

Acheampong, R. A., \& Silva, E. (2015). Land-use/transport interaction modeling: A review of the literature and future research directions. Journal of Transport and Land Use, 8(3), 11-13.

Alonso, W. (1964). Location and land use. Towards a general theory of land rent. Cambridge, MA: Harvard University Press.

Anjomani, A. (1984). The overlaying map technique: Problems and suggestions. Journal of Planning Education and Research, 4, 111-119.

Anjomani, A., Shad, N., \& Saberi, A. (2005). SDSS for land use and environmental planning: An application example. GIS Planet, Proceedings, Spatial Decision Support Systems, S23.

Anjomani, A., Tayebi, A., Nostikasari, D., \& Kharel, G. (2010). Suitability analysis guidebook/training materials: Manual for application of suitability analysis for a selected region in Texas (5-5667-01-P3). Austin, TX: Texas Department of Transportation, Federal Highway Administration.

Banai, R. (2010). Evaluation of land use-transportation systems with the analytic hierarchy process. Journal of Transport and Land Use, 3(1), 85-112.

Batty, M. (1979). Progress, success and failure in urban modeling. Environment \& Planning A, 11(8), 863-878.

Ben-Akiva, M. \& Lerman, S.R. (1985). Discrete choice analysis. Cambridge, MA: MIT Press.

Berechman, J., \& Small K. A. (1988). Modeling land use and transportation: An interpretive review for growth areas. Environment \& Planning A, 20(10), 1285-1309.

Berke, P., Godschalk, D. R., Kaiser, E. J. \& Rodriquez, D. A. (2006). Urban land use planning (5th ed.). Urbana, IL: University of Illinois Press.

Collins, M. G., Steiner, F. R., \& Rushman, M. J. (2001). Land-use suitability analysis in the United States: Historical development and promising technological achievements. Environmental Management, 28, 611-621.

De La Barra, T. (2001) Integrated land use and transport modeling: The TRANUS experience. In R. K. Brail \& R. E. Klosterman (Eds.), Planning support systems: Integrating geographic information systems, models, and visualization tools (pp. 129-156). Redlands, CA: ESRI Press.

Forester, J. F. (1999). The deliberative practitioner: Encouraging participatory planning processes. Cambridge, MA: MIT Press.

Freilich, R., \& White, S. W. (2008). 21st century land development code. Chicago: APA Planner Press.

Friedmann, J. (1973). Retracking America: A theory of transactive planning. New York: Anchor Press.

Garin, R. A. (1966) A matrix formulation of the Lowry model for intrametropolitan activity allocation. Journal of the American Institute of Planners, 32, 361-364.

Godschalk, D. R. (2007). Land use planning challenges: Coping with conflicts in visions of sustainable development and livable communities. Journal of the American Planning Association, 70(1), 5-13. doi.10.1080/01944360408976334

Hansen, W. G. (1959). How accessibility shapes land use. Journal of the American Institute of Planners, 25(2), 73-76.

Hartshorn, T. A. (1992). Interpreting the city: An urban geography (2nd ed.). New York: John Wiley and Sons, Inc.

Haynes, K. E., \& Fotheringham, A. S. (1984). Gravity and spatial interaction models. London: SAGE Publications. 
Hopkins, L. D. (1977). Methods for generating land suitability maps: A comparative evaluation. Journal of American Institute of Planners, 43(4), 386-400.

Hunt, J. D., \& Abraham, J. E. (2005). Design and implementation of PECAS: A generalized system for allocating economic production, exchange and consumption quantities. In M. Lee-Gosselin \& S. Doherty (Eds.), Integrated land-use and transportation models: Behavioural foundations (pp. 253273). Amsterdam: Elsevier.

Hunt, J. D., \& Abraham, J. E. (2007). Theoretical formulation: System documentation technical memorandum 1 (working draft). Retrieved from http://www.hbaspecto.com/pecas/downloads/files/PECASTheoreticalFormulation.pdf. Accessed 5 August 2017.

Iacono, M., Levinson, D., \& El-Geneidy, A. (2008). Models of transportation and land use change: A guide to the territory. Journal Planning Literature, 22(4), 323-340.

Innes, J. E. (1995) Planning theory's emerging paradigm: Communicative action. Journal of Planning Education and Research, 14(3), 183-189.

Johnston, R. A., \& Shabazian, D. R. (2002). UPlan: A versatile urban growth model for transportation planning. Transportation Research Record, 2542.

Johnston, R. A., \& De La Barra, T. D. (2000). Comprehensive regional modeling for long-range planning: Linking integrated urban models and geographic information systems. Transportation Research Part A, 34, 125-136.

Klosterman, R., Brooks, K., Drucker, J., Feser, E., \& Renski, H. (2018). Planning support methods. Savage, MD: Rowman \& Littlefield Publishers.

Klosterman, R. (1990). Community analysis and planning techniques. Savage, MD: Rowman \& Littlefield Publishers.

Kockelman, K., Anjomani, A., Paul, B., Nostikasai, D., Tayyebi, A., \& Kharel, G. (2011). Design and application of accessible land-use modeling tools for Texas regions (Report 5-5667- 01). Austin, TX: TxDOT, CTR, UT. Retrieved from https://texashistory.unt.edu/ark:/67531/metapth326624/

Kockelman, K., Duthie, J., Kakaraparthi. S. K., Zhou, B., Anjomani, A., Marepally, S., \& Kunapareddychinna, K. P. (2008). An examination of land-use models, emphasizing UrbanSim, TELUM, and suitability analysis (Report 0-5667-1). Austin, TX: TxDOT, CTR, UT. Retrieved from https://ctr. utexas.edu/wp-content/uploads/pubs/0_5667_1.pdf

Lindstone, H. W., \& Turoff, M. (Eds.) (1977). The Delphi: Technique and application (2nd ed.). Reading, MA: Addison-Wesley Publishing Company.

Lowry, I. S. (1964). A model of metropolis (RM-4035-RC). Santa Monica, CA: Rand Corporation.

Malczewski, J. (2004). GIS-based land-use suitability analysis: A critical overview. Progress in Planning, 62, 3-65.

Marsh, W. (2010). Landscape planning: Environmental applications (5th ed.). New York: John Wiley and Sons.

McDonald, J. F., \& McMillen, D. P. (2011) Urban economics and real estate: Theory and policy. Malden, MA: Blackwell Publishing.

McHarg, I. (1992). Design with nature (25th-anniversary ed.). New York: John Wiley and Sons.

McHarg, I. L. (1969). Design with nature. Garden City, New York: Natural History Press.

Meyer, M., \& Miller, E. (2001). Urban transportation planning: A decision-oriented approach. New York: McGraw-Hill.

Meyer, M., \& Miller, E. (2013). Transportation planning: A decision-oriented approach. Atlanta, GA: Modern Transport Solutions, LLC. Retrieved from online at http://mtsplan.com/services.html Moeckel, R. (2017). Constraints in household relocation: Modeling land-use/transport interactions that 
respect time and monetary budgets. Journal of Transport and Land Use, 10(1), 211-228.

Putman, S. H. (1983). Integrated urban models: Policy analysis of transportation and land use. London: Pion.

Putman, S. H. (2001) The METROPILUS planning support system: Urban models and GIS. In R. K. Brail \& R. E. Klosterman (Eds.), Planning support systems: Integrating geographic information systems, models and visualization tools (pp. 99-128). Redlands, CA: ESRI Press.

Rodrigue, J. P. (2020) The geography of transport systems (5th ed.). New York: Routledge.

Saaty T. L. (1980). The analytic hierarchy process. New York: McGraw Hill International.

Saaty, T. L. (1994). Highlights and critical points in the theory and application of the analytic hierarchy process. European Journal of Operational Research, 74(3), 426-447.

Sarzynski, A., Wolman, H., Galster, G., \& Hanson, R. (2006). Testing the conventional wisdom about land use and traffic congestion: The more we sprawl, the less we move? Urban Studies, 43, 601-626.

Silva, E., \& Wu, N. (2012). Surveying models in urban land studies. Journal of Planning Literature, 72(2), 139-152.

Taleai, M., \& Mansourian, A. (2008). Delphi-AHP method to survey major factors causing urban plan implementation failure. Journal of Applied Sciences, 8(15), 2746-2751.

Timmermans, H. J. P. (2003). The saga of integrated land-useltransport modeling: How many dreams before we wake up? Paper presented at the 10th International Conference on Travel Behavior Research, Aug. 10-15, Lucerne, Switzerland.

United States Department of Transportation. (2004). Land use planning for small and medium MPOs. Retrieved from http://tmip.fhwa.dot.gov/clearinghouse/docs/general/sams/landuse/landuse.pdf

Veldkamp, A., \& Lambin, E. (2001). Predicting land-use change. Agriculture Ecosystems and Environment, 85(1-3), 1-6.

Waddell, P. (2002). UrbanSim: Modeling urban development for land use, transportation and environmental planning. Journal of the American Planning Association, 68(3), 297-314.

Waddell, P. (2011). Integrated land use and transportation planning and modeling: Addressing challenges in research and practice. Transport Review, 31(2), 209-229.

Waddell, P., Ulfarsson, G., Franklin, J. P., \& Lobb, J. (2007). Incorporating land use in metropolitan transportation planning. Transportation Research Part A, 41(5), 382-410.

Wang, X., \& Von Hofe, R. (2007). Research methods in urban and regional planning. New York: Springer.

Wegener, M. (2014). Land-use transport interaction models. In Fischer \& P. Nijkamp (Eds.), Handbook of regional science. Berlin: Springer.

Wegener, M. (1994). Operational urban models: State of the art. Journal of the American Planning Association, $60(1), 17-29$.

Wilson A. G. (1970). Entropy in urban and regional modelling. London: Pion.

Wooldridge, J. M. (2013). Introductory Econometrics: A modern approach (5th ed.). Mason, OH: Southwestern College Publishing.

Zebardast, E. (2013). Constructing a social vulnerability index to earthquake hazards using a hybrid factor analysis and analytic network process (F'ANP) model. Natural Hazards, 65, 1331-1359.

Zhou, B., \& Kockelman, K. M. (2008). Neighborhood impacts on land use change: A multinomial logit model of spatial relationships. The Annals of Regional Science, 42, 321-340. 